\title{
Niveles de vida, revolución por objetos y revolución industriosa en la Europa moderna: verdades y fantasmas. Meaux y su campiña (Región de Brie), siglos XVIl y XVIII
}

\author{
Standard of living, consumer revolution and industrious revolution in early modern Europe: facts and fantasies. \\ Meaux and its countryside, seventeenth-eighteenth centuries
}

\author{
Gérard Béaur \\ Centre de Recherches Historiques, CNRS \& EHESS, \\ Francia \\ gerard.beaur@ehess.fr
}

\begin{abstract}
Resumen:
Gracias a un conjunto documental de inventarios post mortem (que cubre dos siglos) de la región de Meaux (en Brie, al este de París), este artículo plantea de forma crítica dos conceptos muy en boga actualmente en los trabajos sobre la historia del consumo al final de la Edad Moderna. Se trata, en primer lugar, de la "revolución del consumo", y, en segundo lugar, de la "revolución industriosa" (brillantemente defendida por Jan De Vries), y de su articulación recíproca, o sea, del hecho de que la "revolución industriosa", que se habría producido desde el siglo XVII en Holanda, sería la matriz de la "revolución del consumo". El trabajo estadístico que se hace permite efectivamente constatar una vez más la validez de la hipótesis relativa a la revolución del consumo, estableciendo un calendario temporal y un ritmo determinado, pero también su ámbito y sus limitaciones sociales, tanto para una pequeña ciudad como para el medio rural circundante. En cambio, se pone en duda la validez de la hipótesis de una revolución industriosa, así como la naturaleza excepcional del caso holandés, tal como las defiende De Vries. A partir de sus resultados, este artículo pone de relieve sobre todo la coyuntura económica y la ampliación de la oferta como mejores explicaciones de la nueva actitud de los pobladores de querer trabajar más para poder consumir más.
\end{abstract}

Palabras ClaVe: Revolución del consumo, Revolución industriosa, Meaux, Francia, Historia rural.

\section{ABSTRACT:}

Based on a large corpus of post-mortem inventories from the small town of Meaux and its countryside, in the Brie, very close to Paris, over two centuries, the article proposes a reassessment of two concepts that are currently structuring the field of the history of consumption at the end of the early modern period. These two concepts: "a consumer revolution", on the one hand, and, on the other hand, "an industrious revolution" (brilliantly advocated by Jan de Vries) are supposed to articulate the one with the other. The industrious revolution would be the matrix of the consumer revolution and it would have occurred first in the 17th century in Holland. The statistical processing of our corpus certainly allows us to validate once again the hypothesis of a consumer revolution. It clarifies its calendar, its temporal rhythm, as well as its social scope and limits, both in the town and in the countryside. On the other hand, it calls into question the relevance of the industrious revolution and the exceptionality of the Dutch behavior claimed by Jan De Vries. It argues that the changing economic context and the widening of the supply provide better keys of explanation than a new attitude of the population which would push them to work more, to earn more, and thus to be able to consume more. KEYWORDS: Consumer revolution, Industrius revolution, Meaux, Rural history, Early Modern Europe.

En cada periodo histórico, ${ }^{1}$ la evolución del nivel de vida de los pueblos se sitúa en el centro de las problemáticas planteadas por la historia social, vinculada a la espinosa cuestión de las desigualdades y jerarquías entre los grupos sociales. Como cabía esperar, los historiadores de la Epoca Moderna europea tampoco han eludido la cuestión. Sus conclusiones parecen unánimes: se ha producido una mejora del nivel de vida, por lo menos en siglo XVIII, no tanto percibida a nivel de las remuneraciones e ingresos, tan difíciles de evaluar, sino en el consumo, cuya determinación se piensa más fácil de estimar. El auge del 
consumo habría sido tan intenso que se han impuesto para designarlo los términos de consumer revolution (McKendrick, 1982) o el de révolution des objets, revolución por objetos (Cornette, 1989; Minard, 2000), incluso para antes del siglo XIX, contrariamente a lo que se admitía con anterioridad. Hay al respecto una primera convergencia entre los autores, la misma que ha logrado alterar la cronología que se había efectuado anteriormente (Roche, 1997, 1981; Pardailhe-Galabrun, 1988), a pesar de que no haya todavía una clara explicación de ese movimiento duradero y profundo.

Sin embargo, la tendencia actual de la historiografía asume como verídica la versión proporcionada por Jan De Vries sobre la industrious revolution (revolución industriosa) como factor explicativo del mencionado espectacular progreso del consumo (De Vries, 2008, 1994). Dicha teoría, en resumidos términos, se apoya en la certeza de que la consumer revolution se vincula con una nueva actitud de los hogares, los mismos que se habrían orientado resueltamente hacia un proceso de intensificación del trabajo (incluso femenino e infantil), con la finalidad de ganar más para consumir más. Dicho concepto, importado desde Japón a Europa, impuesto por Hayami desde 1967 (Hayami, 2015), ha tenido mucho éxito para explicar el desarrollo de las fuerzas productivas gracias a la revolución industrial (De Vries, 1994).

Dos afirmaciones conexas, una sobre la cronología y otra sobre el espacio de dicho cambio (o sea, el de las consomption victims), vienen a completar la teoría. Según De Vries, ese proceso se produjo desde la segunda mitad del siglo XVII y, en primer lugar, en las Provincias Unidas (De Vries, 2008). Los otros países, sobre todo del Oeste de Europa, siguieron el ejemplo, pero a trompicones, mientras que los demás se quedaron fuera de ese virtuoso proceso. Con lo que nos encontramos, más o menos implícitamente, en el cuadro de una oposición Norte/Sur, con la primacía holandesa y con el género de explicaciones que suelen enarbolar algunos investigadores, dentro de la comodidad de las soluciones triviales que permiten explicarlo todo. Pero preguntémonos: ¿será de esa manera como ocurrieron efectivamente las cosas?

Nos hemos planteado en este artículo la necesidad de verificar de manera práctica los hechos supuestos por la mencionada teoría, escogiendo para ello un espacio que no sea el de una gran ciudad, ni el de un centro marítimo, ni el de un coto aislado sin intercambios comerciales. Hemos optado por un espacio simple: una pequeña ciudad, Meaux, y sus campiñas, ${ }^{2}$ durante casi dos siglos, desde 1600 hasta 1790 . Es decir, hemos seguido la misma vía que otros tomaron antes que nosotros (Van der Woude y Schuurman, 1980; Baulant, Schuurman y Servais, 1988; Sobrado Correa, 2003; Moreno Claverías, 2018; Béaur, 2017a et 2017b; Béaur, 2018, etc...), esto es, el uso de una fuente de excepcional riqueza, a pesar de su complejidad: los inventarios post mortem. A dicha fuente vamos a plantearle tres preguntas: a) ¿Hubo mejora del nivel de vida durante esos dos siglos?; b) Si fue el caso, ¿ello se correspondió con una consumer revolution?; c) Si fue así, ¿la mencionada consumer revolution fue originada por una industrious revolution?

\section{UN LUGAR, UN MOMENTO, UNA FUENTE}

En honor a la verdad hay que decir que no hemos "escogido" ni el lugar ni la fuente, sino que los hemos "adoptado", aprovechando la casualidad afortunada que fue el registro de fichas realizado por Micheline Baulant (archivista, paleógrafa e historiadora ruralista, lamentablemente desaparecida en 2000, sin haber podido utilizar su registro). Digamos en pocas palabras que los inventarios postmortem son los actos notariales que se establecieron después de un fallecimiento en condiciones particulares, y que, relativamente neutrales desde el punto de vista social, se efectuaron con la finalidad de proteger los intereses de los niños (si el fallecido era uno de los dos padres) o para salvaguardar los intereses de los acreedores, cuando el deudor era el mismo fallecido (Baulant, 1980a, 1980b). De esto se deduce que es muy difícil alterar lo registrado por el notario y que la fuente contenga algún sesgo, siendo casi aleatoria, por lo que se puede cubrir un espectro sociológico amplio y con ello representarse a las diferentes capas sociales.

En principio, los inventarios son exhaustivos y muy precisos: cada objeto, por modesto que sea, aparece registrado, a veces con un sorprendente lujo de precisiones. En función de sus necesidades, el historiador 
puede modificar una base de datos, pero eso no es posible en este caso. Su autora le ha dado un grado de precisión y detalle, no solo en el momento de la recogida de datos sino también en su codificación y en la misma constitución de la base (Baulant, 1979). Esto configura un robusto y rico corpus de datos, con un total de 1136 inventarios recogidos y registrados.

Fuera del siglo XVI (lamentablemente no cubierto, aunque sin excesivas consecuencias para nuestros objetivos), dicho corpus recorre toda la Era Moderna, cubriendo los siglos XVII y XVIII, en los que se inscribe precisamente nuestra problemática. Los inventarios corresponden a los difuntos de Meaux y también a los de las aldeas vecinas. Puede ser que la imagen que se da allí de la distribución de la población contenga algún sesgo, pero no por ello deja de ser sugestiva.

\section{GRÁFICO 1}

Estructura social de la población de la Región de Brie, según los inventarios post mortem

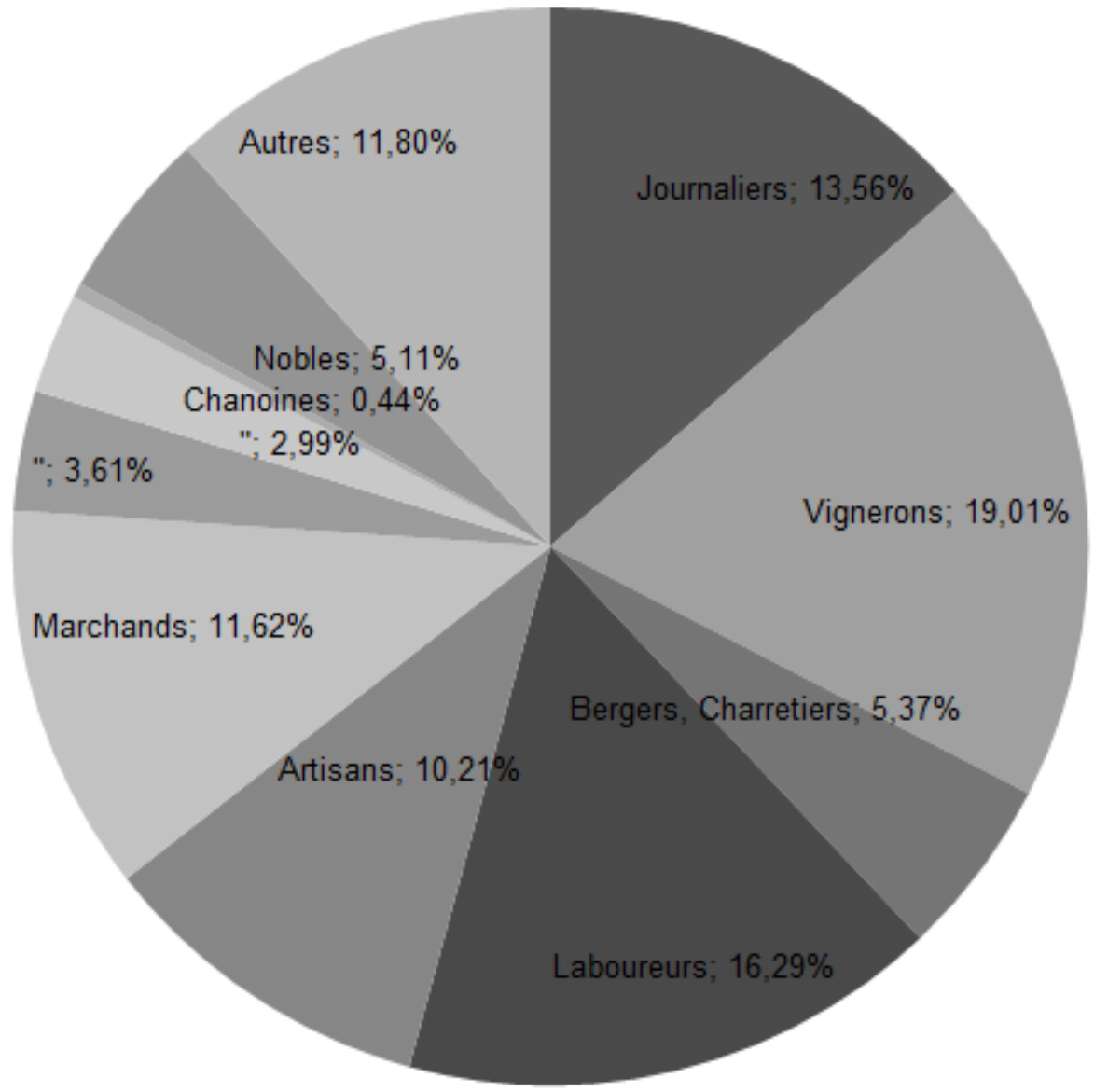

Fuente: Archivos Notariales de la Región de Brie y la Ciudad de Meaux. Datos compilados por Micheline Baulant en los archivos jurisdiccionales señoriales: Serie B, Archivos Departamentales de Sena y Marne, o Serie Z2 de los Archivos Nacionales; completados con los Archivos Notariales, Serie E, Archivos Departamentales de Sena y Marne. Estadísticas obtenidas a partir de 1052 inventarios.

La pequeña ciudad de Meaux, situada en las orillas del Marne, es decir, en conexión con París, contaba con alrededor de 5.000 habitantes. Su reputación residía en el hecho de haber contado en su iglesia catedral, bajo Luis XIV, con el famoso obispo Jacques-Bénigne Bossuet, el “Águila de Meaux" (Wilmart, 2013). Había además algunos funcionarios, canónigos, comerciantes y artesanos; nada que saliera de lo común. Hay que indicar que buen número de burgueses y nobles residentes en la modesta Meaux preferían recurrir a los notarios parisinos (como tradición familiar), al momento de tratar sus asuntos. Esto quiere decir que 
la estructura social de nuestra muestra debe de tomar en cuenta dicho factor, que puede eventualmente deformarla.

En el entorno de la ciudad se desplegaba un valle densamente poblado, serpenteando por planicies limosas, con aldeas de viñateros, micropropietarios y asalariados agrícolas simultáneamente. La gran fertilidad del suelo permitía el cultivo de cereales, pero también favorecía la producción del famoso queso de Brie (el "Brie de Meaux"). Los ricos (y muy ricos) agricultores, los denominados laboureurs (Mireau, 1958) dominaban sobre una población de jornaleros más o menos empobrecidos. Era muy posible que fuesen esos ricos empresarios agrícolas los que precisamente optaran por no recurrir a los notarios locales de Brie, lo que introduce un sesgo al privarnos de la "clientela" más favorecida. Así, al examinar nuestra muestra debemos guardar en mente la idea de que el nivel general de vida ha sido seguramente subestimado, lo mismo que la precocidad en el modo de consumo. Nuestros datos nos conducen entonces hacia lo que podemos designar como consumo popular, lo que sería un defecto de la muestra si no fuera justamente lo que estamos buscando.

MAPA 1

Meaux y la Región de Brie

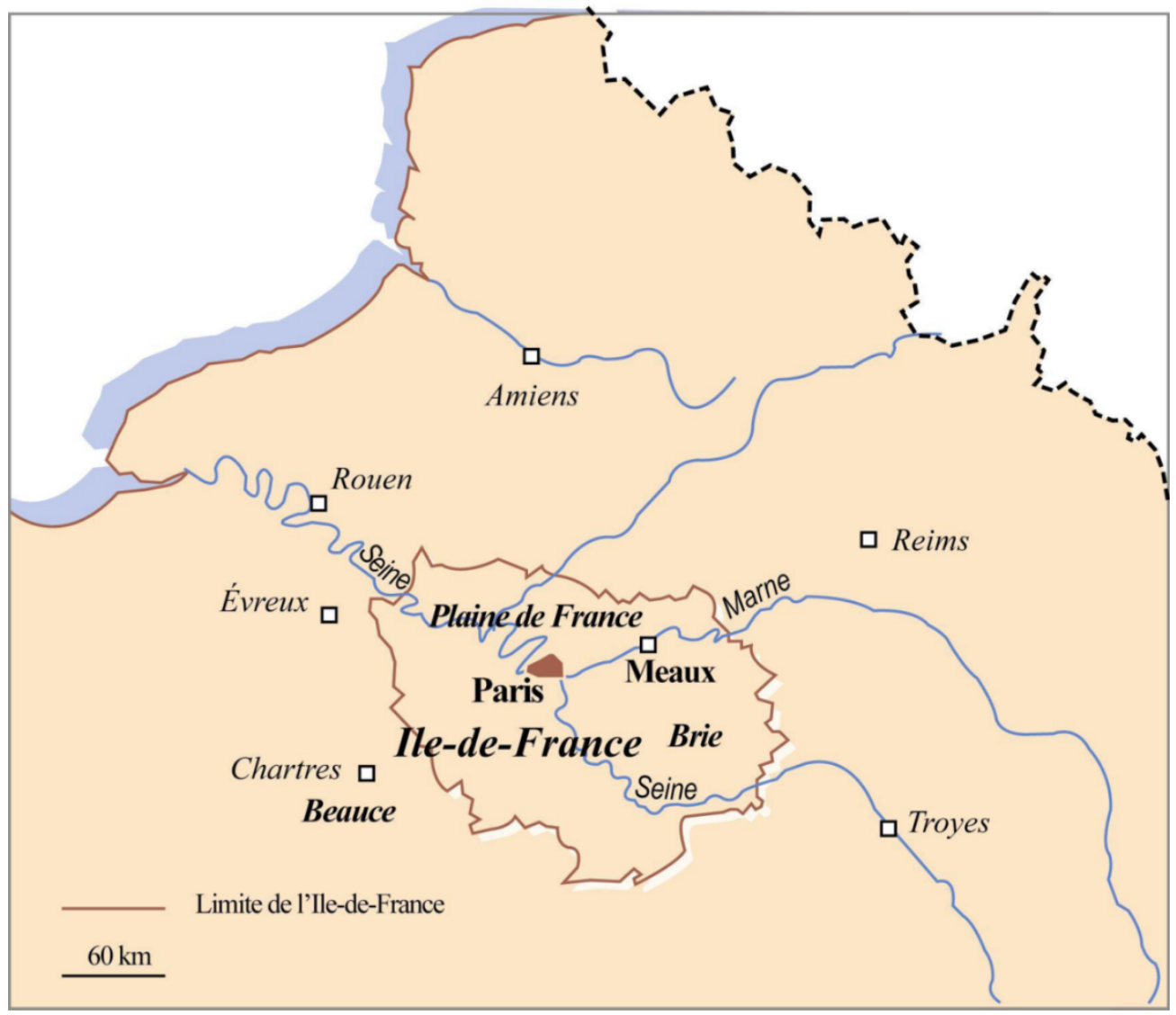

Fuente: mapa A. Varet-Vitu (CNRS, CRH, Paris)

\section{Explotación DE LA MUESTRA}

La aguda precisión de los registros de Micheline Baulant constituye un desafío para el análisis. Ya se había dado cuenta ella misma de que si la base de datos permitía caracterizar el conjunto del consumo de los difuntos, a partir de lo que dejaban al morir, era bastante difícil considerar toda la información, si se deseaba elaborar un índice sintético. Esta fue la razón por la cual ya había empezado ella misma a efectuar una selección de indicadores para verificar si aumentaba o no el nivel de vida, y creó para ello cinco categorías de objetos, 
de usos y prácticas, calificados como sintomáticos (Baulant, 1992, 1990, 1989). Es decir, los jerarquizó en función del grado de utilidad o su carácter más o menos indispensable, o según como reflejaran la adopción de cierta comodidad o lujo en el modo de vida de los difuntos.

Después de recuperar y decodificar los ficheros de registro de M. Baulant hemos efectuado pruebas para adoptar los criterios operativos, seleccionando para ello 85 indicadores (muchos de los cuales también lo habían sido por M. Baulant) cuya lista aparece en el cuadro siguiente. Los hemos distribuido en cuatro categorías (y no cinco), desde el consumo de productos de base hasta los de lujo, o aquellos que testimonian de una opción nueva por productos de "civilización" o la adopción de cierta comodidad. Es decir, hemos seguido la clasificación hecha por la autora, luego de años de trabajos y pruebas, adaptándola ligeramente a los datos, y conservando los elementos significativos. Su clasificación, repetimos, reproduce una verdadera jerarquía de uso de los bienes, partiendo en primer lugar de aquellos comunes de los hogares (o sea, los elementos básicos y necesarios de las familias), pasando, en segundo lugar, por los bienes que reflejan la búsqueda de condiciones de vida más confortables (que sin significar derroche alguno buscan sin embargo una mayor comodidad). Luego, en tercer lugar, los bienes que traducen la voluntad de demostrar ostentosamente un nivel de vida más refinado, mediante el consumo de productos más caros o de lujo, dejando, en cuarto lugar, para terminar, a los bienes de civilización, situados ya en otro universo, el de la emergencia de unos gustos intelectuales, artísticos o científicos, que se alejan más aún del consumo de la cotidianidad.

Siguiendo en ello el ejemplo de M. Baulant, hemos anotado solamente la ausencia o la presencia de cada objeto y no tanto el número de veces que aparece o el valor de los objetos (Pérez García, 1997), con la finalidad de simplificar el tratamiento de los datos y para poner de realce el hecho de que lo que interesa es la aparición de dichos objetos en los interiores rurales o urbanos, más que la intensidad de su uso.

\section{CUADRO 1}

Los indicadores

\begin{tabular}{|c|c|}
\hline $\begin{array}{l}\text { Serie: Civilización (17 rúbricas) } \\
\text {-Decoración: cuadros, grabados, estampas } \\
\text {-Medida y cálculo: balanzas, termómetros } \\
\text { - Horquillas } \\
\text { - - } \text { - Vuchillos de mesa, de mango para bebery jarras de vidrio } \\
\text { - Libros y bienes de lectura } \\
\text {-Especias o condimentos exóticos: pimienta, nuez moscada, azúcar } \\
\text {-Bebidas excitantes y sus recipientes: té, café, chocolate, licores y } \\
\text { tabaco } \\
\text {-Objetos de piedad: crucifijos, pilas de agua bendita } \\
\text {-Bienes de escritura: registros, escritorios, tinteros, } \\
\text {-Materias exóticas: marfil, ébano } \\
\text { - Objetos e instrumentos musicales } \\
\text {-Juegos de cartas, bolos, ludo, fichas, solitarios, petanca, ajedrez, } \\
\text { dominó, guijarros y huesecillos } \\
\text {-Objetos para medir el tiempo: relojes personales, despertadores } \\
\text {-Variedad de ambientes: oficinas, antesalas, retretes, salones, } \\
\text { comedor } \\
\text {-Condimentos locales: mostaza, uvas agraces, vinagre } \\
\text {-Apertura al mundo: mapas, binoculares, anteojos }\end{array}$ & $\begin{array}{l}\text { Serie: Lujo (19 rúbricas) } \\
\text {-Tres habitaciones o más } \\
\text {-Vajilla de porcelana } \\
\text {-Cristal, mármol } \\
\text {-Vajilla de plata } \\
\text {-Cretona y terciopelo como superficie } \\
\text { de muebles } \\
\text {-Decorados de madera y ébano } \\
\text {-Asadores } \\
\text {-Poissonnière (utensilio para cocer } \\
\text { pescado) } \\
\text {-Cómodas } \\
\text {-Secretarios } \\
\text {-Parteluces } \\
\text {-Péndulos, relojes de pared } \\
\text {-Mesas de apoyo } \\
\text {-Tapices y cortinillas } \\
\text {-Cortinas transversales } \\
\text {-Mamparas } \\
\text {-Paraguas y parasoles } \\
\text {-Armas: espadas y revólveres } \\
\text {-Estufas, hornos }\end{array}$ \\
\hline $\begin{array}{l}\text { Serie: Comodidad (22 rúbricas) } \\
\text {-Una o dos habitaciones con cama } \\
\text {-Loza } \\
\text { - Hojalata } \\
\text {-Cobre rojo } \\
\text {-Fuelles } \\
\text {-Bandeja de hornear o grasera } \\
\text {-Espumaderas } \\
\text {-Ensaladeras } \\
\text {-Soperas } \\
\text {-Calentadores de cama } \\
\text {-Fuentes } \\
\text {-Espejos } \\
\text {-Armarios } \\
\text {-Aparadores } \\
\text {-Sillones, caquetoire (pequeño sillón de conversación) } \\
\text {-Rodapiés de cama, baldaquín, } \\
\text {-Almohadas } \\
\text {-Manteles, tapetes, alfombras de mesa } \\
\text {-Toallas } \\
\text {-Planchas } \\
\text {-Carbón } \\
\text {-Calentadores }\end{array}$ & $\begin{array}{l}\text { Serie: Necesario en Vida Doméstica } \\
\text { (27 rúbricas) } \\
\text {-Estaño } \\
\text {-Cremalleras } \\
\text {-Pinzas } \\
\text {-Morillos } \\
\text {-Palas de horno } \\
\text {-Marmitas, calderos } \\
\text {-Parrillas, pinchos } \\
\text {-Trípodes } \\
\text {-Sartenes y cazuelas } \\
\text {-Lámpara, luces y antorchas } \\
\text {-Candelabros, linternas } \\
\text {-Cofres, baúles } \\
\text {-Artesas y paneras } \\
\text {-Mesas } \\
\text {-Bancos, banquillos } \\
\text {-Sillas } \\
\text {-Cabeceras de cama } \\
\text {-Colchones } \\
\text {-Sábanas } \\
\text {-Frazadas } \\
\text {-Placas de planchar } \\
\text {-Planchas } \\
\text {-Saladores } \\
\text {-Cucharones } \\
\text { - Hornillos } \\
\text {-Platos, escudillas } \\
\text {-Cubetas y tinas }\end{array}$ \\
\hline
\end{tabular}




\section{3. ¿ELEVAción DEL NIVEL DE VIDA?}

En un primer momento, el nivel de vida se ha medido para cada medio siglo y se ha establecido un índice, calculado a partir del número de veces de aparición de los 85 indicadores de cada inventario, estimando el promedio para cada periodo. Con ello se percibe rápidamente que, si hubo un estancamiento en el siglo XVII, el aumento fue nítido durante la primera mitad del siglo XVIII, para volverse luego sumamente rápido durante su segunda mitad, antes de la Revolución Francesa. Es decir, se produjo indiscutiblemente durante todo el periodo de referencia una mejora en el nivel de vida promedio de la población de la Región de Brie, no obstante este hecho tuvo lugar sobre todo durante el siglo XVIII.

\section{GRÁFICO 2}

La mejora del nivel de vida (Meaux y la Región de Brie)

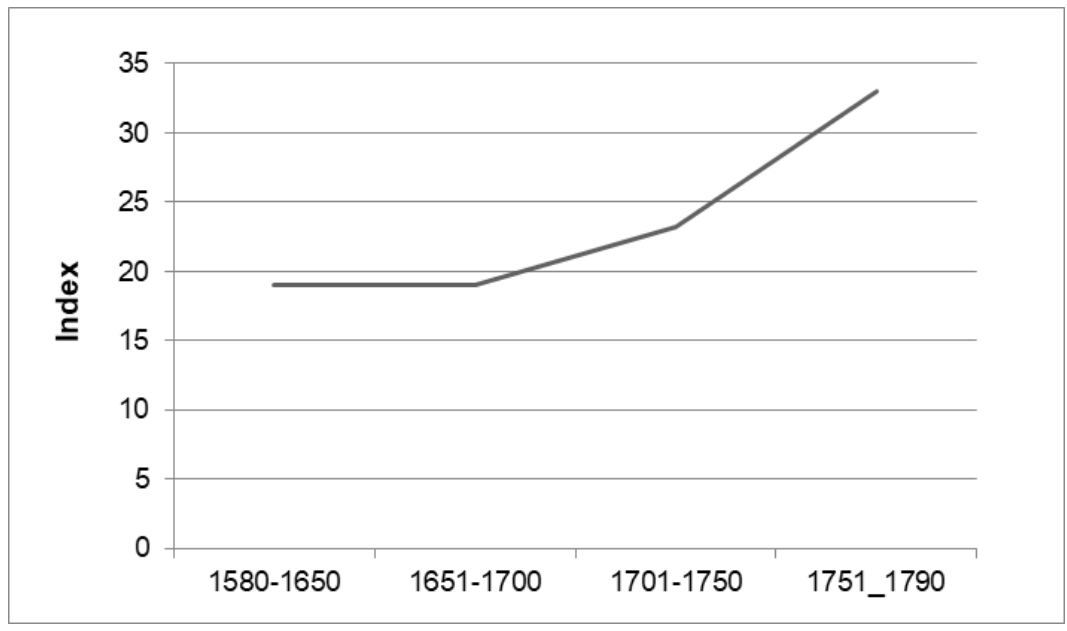

Fuente: Ver Gráfico 1. Estadísticas obtenidas de 1132 inventarios.

Empero, si nos ponemos a comparar lo que ocurrió en la ciudad y en el campo, veremos que la evolución fue bastante diferente. Así, con un crecimiento más rápido del mencionado índice, fueron los difuntos de la ciudad de Meaux los que más aprovecharon dicha mejora. Es más, cabe decir que se trata de un aumento continuo, constante durante los dos siglos, que se acentúa ciertamente durante el XVIII. Lo que se diferencia de la evolución del campo, en donde se observa el estancamiento antes mencionado durante el siglo XVII, antes de asistir a un arranque temprano al inicio del XVIII. Es entonces la ciudad la que mejor aprovecha la evolución, y el campo sigue un impulso que proviene del medio urbano.

\section{GRÁFICO 3}

Evolución del nivel de vida de la población urbana y rural (Meaux y la Región de Brie)

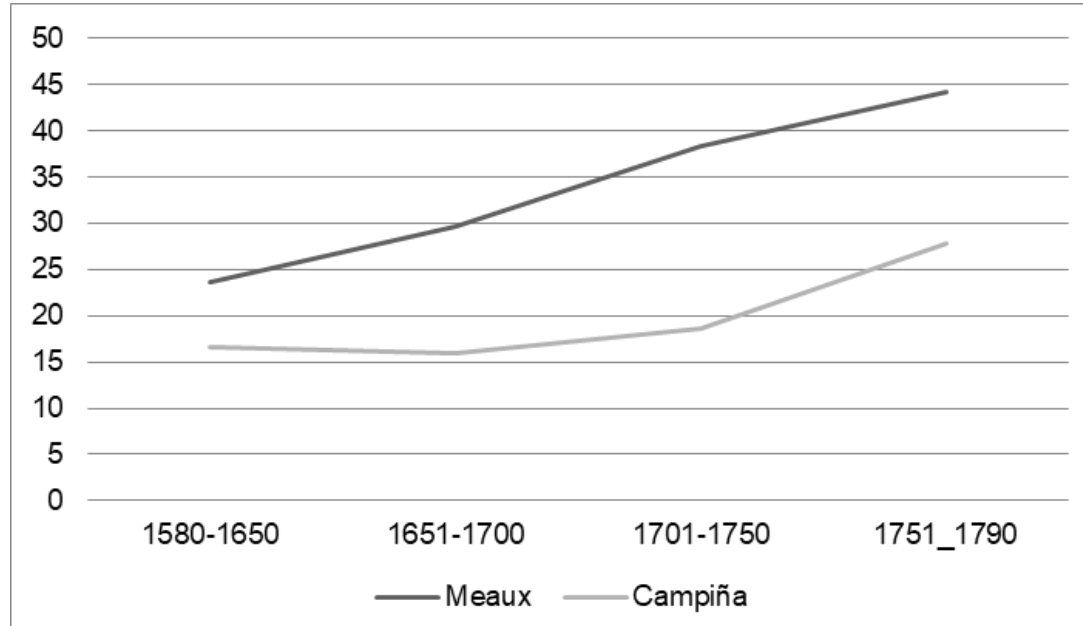

Fuente: Ver Gráfico 1. Estadísticas obtenidas de 1132 inventarios 


\section{4. ¿UNA REVOLUCIÓN DEL CONSUMO?}

Esa elevación en el nivel de vida, aunque matizada por sus contrastes, ¿habrá sido acompañada por una verdadera revolución en el modo de consumo? Es aquí donde la distinción efectuada entre bienes necesarios o indispensables y los de bienestar o comodidad adquiere todo su sentido. La clasificación de la muestra proporciona un enfoque original con respecto a la pregunta planteada, al tomar en cuenta la naturaleza de los cambios de consumo que se han operado.

Rápidamente nos damos cuenta de que las mejoras corresponden especialmente a las rúbricas de lujo, civilización y sobre todo de comodidad. Se ha producido entonces una mejora cualitativa del cuadro y el modo de vida de la población. Para las 28 rúbricas incluidas en lo necesario, la mejora es lenta, con un índice que no aumenta más de 2 puntos. En promedio, los difuntos solo poseen una quincena de elementos, contra trece más o menos, dos siglos antes. En cambio, el índice de comodidad triplica (gana 6 puntos), como los de civilización y lujo, aunque con un ligero desfase temporal. Está surgiendo entonces un nuevo tipo de consumo de mejora del cuadro de vida, pero con mayor intensidad en los bienes de comodidad.

GRÁFICO 4

Evolución del consumo por indicadores
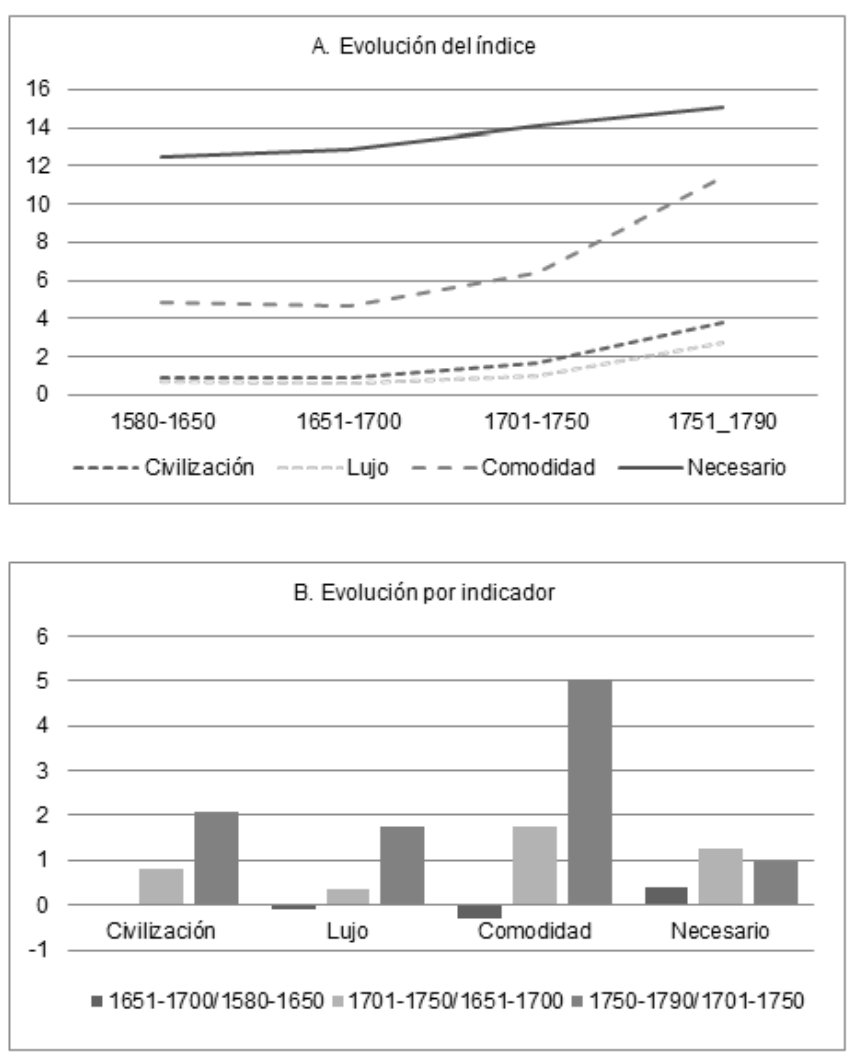

Fuente: Ver Gráfico 1. Estadísticas obtenidas de 1132 inventarios.

Esta revolución del consumo se verifica por todos lados y no solo en las Provincias Unidas, como lo afirma De Vries, es decir, en Amsterdam (MacCants, 2007) o en Holanda rural (Schuurman, 2011), sino también en Cataluña, en torno a Gerona, o más al sur, en Bittles (Congost, 2017; Moreno Claverías, 2017), o en París (Roche, 1997, 1981; Pardailhé-Galabrun, 1988), o en sus campiñas aledañas durante el siglo XIX (Herment, 2017). Pero también en Lisboa (Durães, 2012), en Inglaterra (Weatherill, 1988), con matices, tanto en Kent como en Cornouaille (Overton, Whittle, Dean y Hann, 2004), o en las mismas colonias inglesas de América (Shammas, 1990). Más sábanas, camisas, abundante ropa, agradable y cómoda (Baulant, 2001; Pellegrin, 1986), más toallas, más cucharas y tenedores, más armarios y no solo cofres, en la Región de Poitou (Peret, 1986) o en Cataluña (Moreno Claverías, 2017). El alumbrado mejora, la cristalería, loza y 
alfarería se vuelven comunes, las superficies de los muebles y los tapizados son más elaborados (Baulant, 1989). De raros, desconocidos o casi inexistentes que eran, los manteles, la vajilla de plata, la loza, o el consumo de café y té, se volvieron, si no comunes, por lo menos más frecuentes hacia fines del siglo XVIII. Esa evolución pudo efectivamente observarse, como la que ya señalara $\mathrm{D}$. Roche en los medios populares parisinos, para elmobiliario, los utensilios de cocina, los objetos decorativos o de aseo y tocador (Roche, 1981, 144-158). En realidad, la Región de Brie no tiene nada de original.

Desde esa óptica también conviene distinguir entre la ciudad de Meaux y sus campiñas. Si agrupamos los tres indicadores que parecen correr simultáneamente, Comodidad/Lujo/Civilización, bajo el término genérico de superfluo, su diferencia con necesario sobresale nítidamente. Tanto en la ciudad como en el campo este último permanece invariable, mientras que lo superfluo aumenta rápidamente, y abre una brecha entre su mayor aumento en la ciudad con respecto al campo. Si lo superfluo urbano sube ligeramente durante la segunda mitad del siglo XVII, durante las dos mitades del XVIII aumenta vigorosamente. Por su lado, en las campiñas, no hay subida en el siglo XVII y la hay muy modesta hasta mediados del XVIII. El arranque se produce en el último periodo, en vísperas de la Revolución, con un ritmo tardío pero que no deja de ser espectacular. No es que el campo no acceda a una nueva comodidad, lo que ocurre es que el proceso se da con mayor lentitud y menor amplitud que en la ciudad.

En resumidas cuentas, las novedades vienen de la ciudad, pero se difunden paulatinamente, con retraso, en los medios rurales. Se produce efectivamente una revolución del consumo, aunque más marcada en el medio urbano, lo que no constituye verdaderamente una sorpresa. Son los desfases que ya se habían observado en Lisboa o en Barcelona con respecto a sus campiñas (Durães, 2012; Moreno Claverías, 2017).

\section{GRÁFICO 5}

Evolución del consumo de los productos necesarios y los "superfluos" en la ciudad de Meaux y las campiñas de la Región de Brie

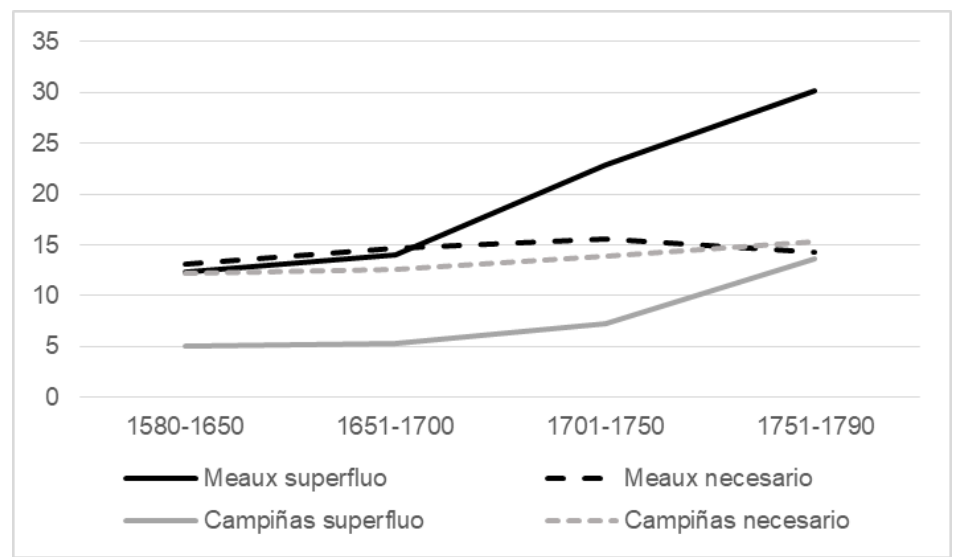

Fuente: Ver Gráfico 1. Estadísticas obtenidas de 1132 inventarios (Meaux, 176 y la Región de Brie, 956)

\section{5. ¿UNA REVOLUCión Industriosa?}

Hasta aquí, todas las estadísticas se han establecido sobre la base de promedios, para periodos de cincuenta años. Ahora bien, con el fin de captar mejor los movimientos más cortos, se tenía que afinar la periodización, lo que conllevaba modificar significativamente el tratamiento de los datos para contrarrestar los efectos que provoca la reducción de la escala de observación. Para ello, con el fin de evitar la fragilización de las conclusiones que se extraigan, se han introducido dos cambios. Al respecto, conviene recordar que cuando se trabaja con muestras más pequeñas se corre el riesgo de falsear los promedios, al incluir datos excepcionales, con algún inventario que podría sesgar, hacia arriba o hacia abajo, los resultados. Por ello, en primer lugar, se ha escogido la mediana en lugar del valor promedio, con la certeza de que se pueden así evitar las deformaciones producidas por algún inventario, o un grupo de estos, de poca representatividad. En 
segundo lugar, hemos tenido que resignarnos a reducir el espacio temporal de observación, sabiendo que el número de inventarios es más pequeño durante la primera mitad del siglo XVII. ${ }^{3}$ Por ello hemos optado por comenzar en 1651, a mitad de siglo, aunque situando las dos décadas precedentes (1631-1650) como elementos de referencia. Asumimos que la que hacemos es una renuncia razonable, en la medida en que la primera parte del siglo es casi inmóvil y que lo esencial parece jugarse en su segunda mitad.

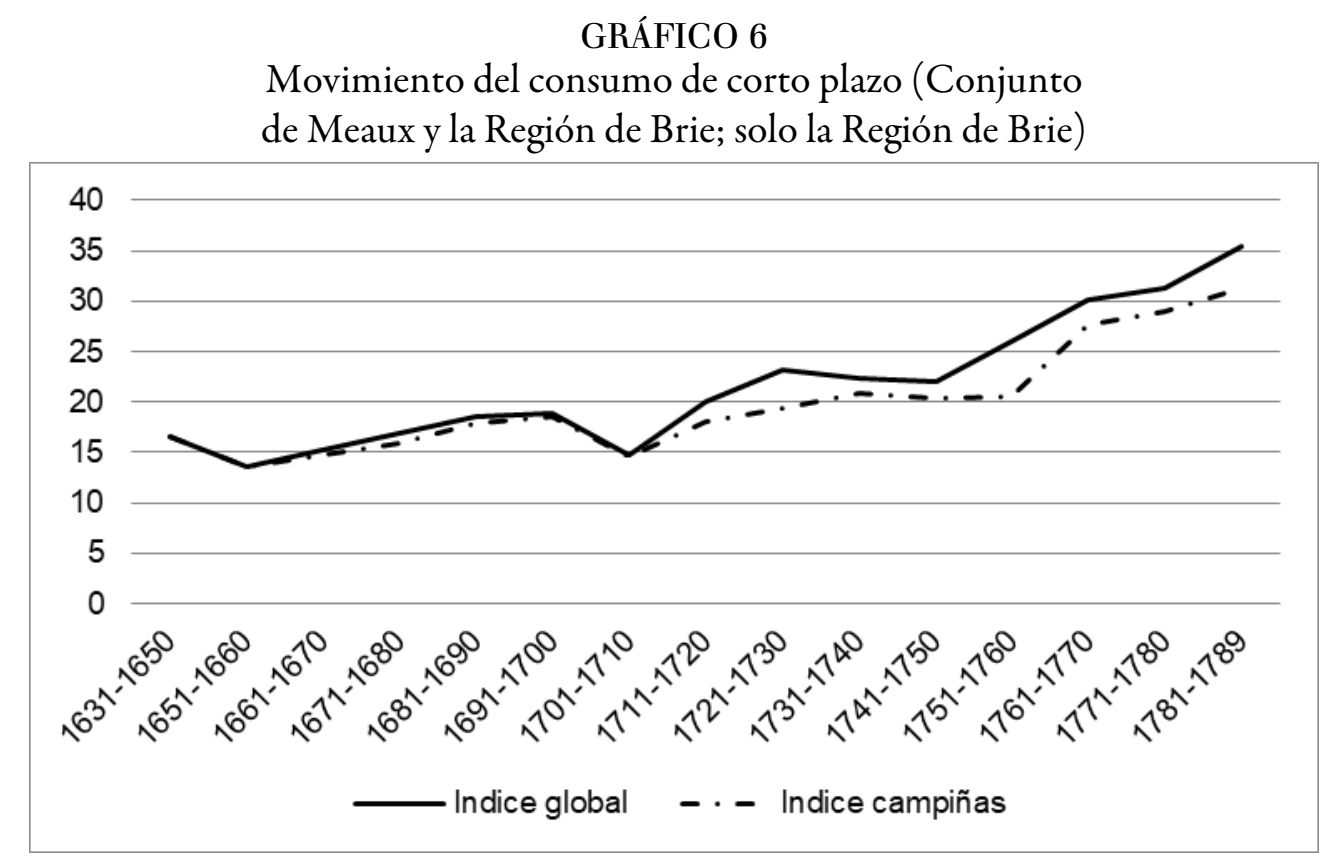

Fuente: Ver Gráfico 1. Estadística obtenida de 1074 inventarios (153 para Meaux, 921 para la Región de Brie).

La perspectiva se modifica totalmente y se matizan las constataciones hasta ahora efectuadas. La primera sorpresa es que el siglo XVII no es tan inmóvil como se pensaba. El bajón de mitad de siglo con respecto al periodo anterior está en contraste con el aumento substancial que se produce entre 1661-1690, antes de estancarse a fines de siglo y volver a caer brutalmente en la década de 1701-1710. Sin embargo, este nuevo bajón es de corta duración y el índice vuelve a subir con rapidez hasta incluso superar los niveles anteriores a su caída. No obstante, se trata de un arranque más o menos vacilante ya que el nivel de vida parece marcar el paso durante la primera mitad del siglo XVIII, antes de alzar el vuelo en su segunda mitad, lo que de hecho nos introduce una segunda sorpresa, al no ser la curva de ascenso tan lineal como se hubiese podido suponer.

Pero hay otro elemento que también llama la atención que es el desfase entre la curva del nivel de vida del conjunto (Meaux y Región de Brie), o sea, el índice global, y la curva de las campiñas, graficada por separado. Si bien la evolución es más o menos idéntica, se destacan sin embargo dos diferencias claras. Por un lado, el desfase entre los índices crece desde inicios del siglo XVIII, cuando hasta ese entonces los mismos habían avanzado muy cercanos. Por otro lado, surge un desfase de más o menos una década, cuando el movimiento se recupera y asciende (después de un bajón), tal como lo hemos indicado anteriormente. Es decir, se opera una ruptura en la consumer revolution. Si el nivel de vida aumenta en general, en un determinado momento se produce un divorcio entre la ciudad y el campo; la mejora del nivel de vida ha sido de hecho más precoz, rápida e intensa en el medio urbano que en la sociedad rural.

Tratemos de extraer algunas conclusiones de esta incursión en el corto plazo, puesto que la cronología de la revolución del consumo parece ser bastante diferente de la descrita anteriormente. No es cierto que no haya ocurrido nada durante el siglo XVII; se produjo en verdad un arranque del consumo en su segunda mitad, aunque luego fue contrarrestado. El perfil aplanado de la curva era en realidad el fruto de la aglutinación de niveles muy opuestos y contrastados, con un movimiento extraordinariamente accidentado que neutralizaba 
la observación de la evolución que ocurría en el mediano plazo. O, para decirlo de otra manera, a partir de ahora tenemos que explicar tanto el auge del índice -durante la segunda mitad del siglo XVII- como su derrumbe -que ocurre entre fines del siglo XVII e inicios del XVIII- de la misma manera que debemos hacerlo con el disparo de tendencia que tiene lugar en el siglo XVIII.

Ese itinerario accidentado y diferenciado nos plantea un problema, a saber, ¿cómo validar el concepto de revolución industriosa cuando la "sed de consumo" efectúa esos movimientos de yoyó? A la vez, hay otras cuestiones que parecen desafiar dicha teoría. Cuando se retoma la cronología de medio siglo en medio siglo, y se analiza la profesión de los difuntos o su estatuto social, se obtiene un curioso resultado que nos mueve a formular la pregunta sobre quiénes son los que sacan provecho de esa revolución del consumo. ¿Acaso son los más humildes, o sea, los que deciden trabajar más para consumir más?

Si bien es cierto que se produce una continua y lenta mejora del nivel de consumo de los jornaleros y viñateros, ubicados junto con todos los trabajadores en las escalas sociales inferiores, no son ellos los principales beneficiarios de esa revolución. En cambio, los laboureurs, o sea, sus "patrones" sí que muestran una mejora constante y mucho más fuerte de su nivel de vida. Ciertamente, en rigor, se puede admitir que dichos empresarios agricultores hayan optado por incrementar sus esfuerzos y aplicarlos en su propia explotación agrícola, pero aun si así fuera ya sería menos significativo, puesto que no eran ellos los que corrían con el mayor esfuerzo productivo. Simultáneamente, podemos agregar que los comerciantes y artesanos también experimentan un significativo aumento de su nivel de vida. Esto podría llevarnos a admitir que ellos también participan de esa voluntad de intensificación del trabajo, si no fuera por el ya mencionado derrumbe de consumo de fines del siglo XVII, inexplicable a primera vista.

GRÁFICO 7

Los beneficiarios de la Revolución del Consumo

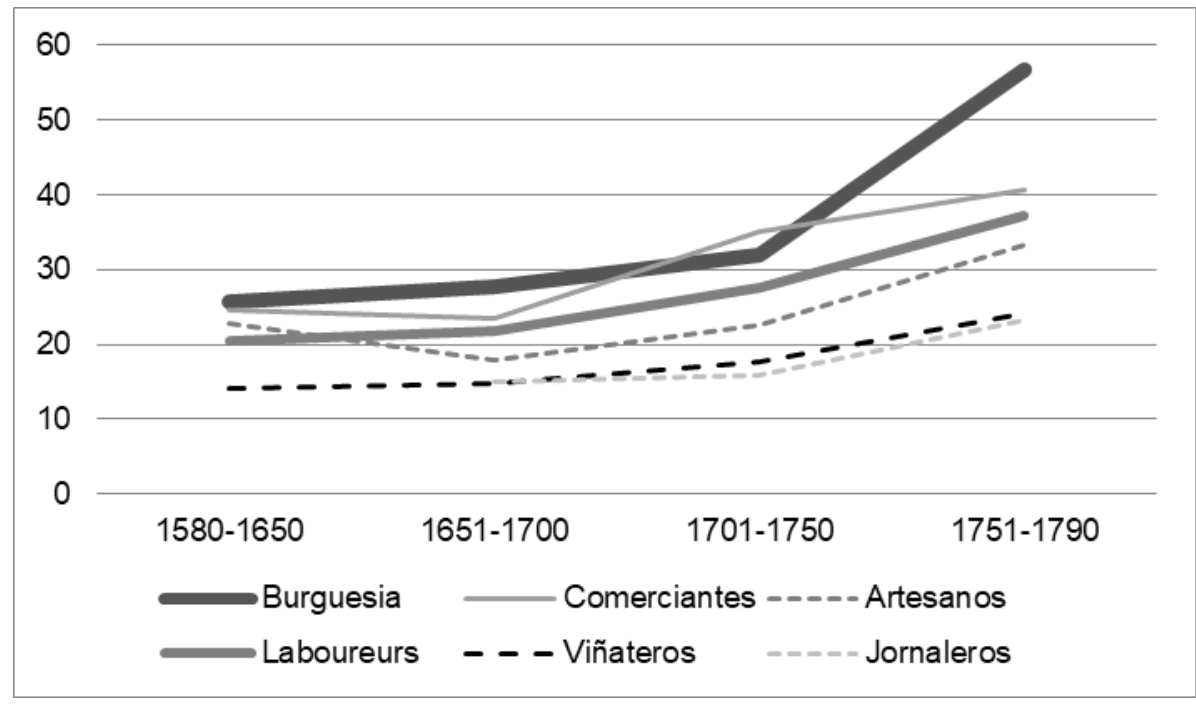

Fuente: Ver Gráfico 1. Estadísticas obtenidas de 879 inventarios.

Ahora bien, el asunto se vuelve casi enigmático cuando nos apercibimos de que los que sacan el mayor provecho del aumento del nivel de vida son los rentistas (burgueses, funcionarios y sobre todo los canónigos de la iglesia catedral), de quienes nos cuesta creer que hayan acrecentado su esfuerzo productivo para consumir mejor. El corolario es que nos hallamos delante de un desfase con consecuencias de gran alcance. Si todos sacan provecho de esa bonanza del consumo, la brecha tiende a abrirse entre unas élites que se benefician plenamente de ella y una masa de gente que está lejos de acceder al mismo nivel de opulencia. Esa desigualdad progresiva y su percepción no menos creciente nutren muchas frustraciones, que acumulan un potencial revolucionario dispuesto a estallar en lo que será el final del Antiguo Régimen. 
Tratemos de resumir. Nos encontramos ante numerosos indicios que sugieren que la sed de consumo no fue el motor de la revolución del consumo, a saber: mediocridad del aumento del nivel de vida de los más pobres, fuerte incremento para aquellos que no están comprendidos dentro del proceso productivo, y, por último, una inexplicable baja del ritmo de evolución, en la mitad del periodo considerado.

\section{Primeras conclusiones previas}

Siguiendo esas constataciones, podemos formular algunas primeras conclusiones previas.

1) La idea según la cual la revolución del consumo se habría producido más pronto en las Provincias Unidas que en otras partes es más que cuestionable. En la región de Meaux, o sea, en una zona después de todo bastante común, el nivel de vida también creció en la segunda mitad del siglo XVII, es decir, al mismo tiempo que en el presunto templo del progreso y el trabajo. Incluso podríamos hacer retroceder en el tiempo la mencionada revolución, al haber detectado en los inventarios de los difuntos -en el momento de su fallecimiento- bienes que seguramente no habían adquirido e introducido en su nivel de vida al instante de morir, sino mucho antes, en un periodo anterior de su ciclo de vida.

2) Aunque la composición de la muestra hubiera podido influir en el resultado, podríamos afirmar que nos situábamos, al momento de iniciarla, en un punto elevado, o sea, las décadas de 1631 a 1650, por lo que seguramente sería necesario que tuviésemos que anticipar más aún el punto de arranque de dicho cambio. Pero lo más importante aún es la primera ruptura que se manifiesta durante la década de 1651-1660, lo que hace suponer que se produjo entonces un retroceso brutal del nivel de vida. Sin embargo, dicha fractura es menos significativa todavía que la segunda, la que se observa medio siglo más tarde, durante la década 1701-1710, y que se opone al incremento anterior de más de tres décadas. ¿Qué ocurrió entonces en 1651-1660 y sobre todo en 1701-1710? Sabemos que la primera de las décadas mencionadas coincide con una fase de la guerra de Francia contra España, pero sobre todo con la guerra civil interna que se conoce como la Fronde y que tuvo especiales repercusiones en la región parisina (cercana a Meaux y a la Región de Brie). Las tropas reales y las de la Fronde, el príncipe Condé y el vizconde de Turenne, cada uno por su lado y a su manera, compitieron en devastar y asolar el campo. La terrible hambruna de 1661 fue ulterior y sus efectos fueron probablemente remediados por la larga prosperidad que acaeció luego, aun cuando hubiese podido incidir negativamente en la recuperación del índice durante la década 1661-1670. Pero estamos aquí en el terreno de las hipótesis.

Cuando ocurre la segunda ruptura, entre 1701-1710, ya contamos con evidencias más sólidas. Otra vez nos hallamos, sin embargo, en plena guerra. En primer lugar, la que los franceses denominan Guerra de la Liga de Augsburgo (1689-1697), y, sobre todo, en segundo lugar, la Guerra de Sucesión de España (1701-1713). Otra vez las espantosas hambrunas, en 1693-1694 y 1709, que con certeza socavaron los equilibrios familiares y afectaron especialmente la región cerealera que estamos estudiando, muy vulnerable cuando la cosecha de trigo es mala (Lachiver, 1991), con una "cereza sobre el pastel” representada por la sobrecarga fiscal con el fin de apoyar el esfuerzo de guerra. Ni siquiera los laboureurs lograron eludir esa serie de catástrofes (Moriceau, 1994, pp. 579-612). Aquí también los efectos tardíos descargaron todo su peso para quebrantar el consumo, después de los suplicios del hambre de 1693-1694 (que se cobraron más de un millón de víctimas en Francia), para luego conjugarse con la catástrofe de 1709. ¿Cómo no entender que el consumo disminuyera?

3) La muerte de Luis XIV, en 1715, señaló efectivamente un punto de inflexión. Ciertamente, habrá nuevos conflictos, pero las batallas ya llevarán nombres extranjeros. Ciertamente, volverá a haber escaseces y hambrunas, pero sin comparación con las terribles crisis de miseria de fines del siglo XVII y comienzos del XVIII. Ciertamente, no faltarán los impuestos ni las amargas quejas de los franceses, pero la presión fiscal no se agravará. Se entiende entonces que se produjeran la adquisición de nuevos productos y la mejora del nivel de vida. En resumen, parece haberse dado una buena correlación entre el aumento del consumo y la coyuntura económica, política y fiscal, bastante mayor que la que pudiera establecerse entre dicho aumento y 
una nueva actitud de los hogares. No se trataba entonces de que hubiese aparecido una nueva sed de consumo, que se habría despertado para cambiar el modo de vida, y, podríamos agregar, nada probaba que dicha sed hubiese provocado un esfuerzo productivo acrecentado.

\section{SEgundas CONCLUSIONES PREVIAS}

Pero hay además unas segundas conclusiones previas que nos parece oportuno explicitar.

1) Es evidente que las categorías sociales más pobres y numerosas, las que abrigan en su seno a jornaleros y viñateros, han atravesado por una mejora efectiva de su nivel de vida, pero no es menos cierto el hecho de que solamente les correspondieron las migajas de la revolución del consumo. Al respecto podríamos preguntarnos, ¿̇cómo hubiera podido producirse una distribución diferente? Existen efectivamente pocos argumentos que pudieran corroborar la tesis de un aumento de sus ingresos. Bien sabemos que estos no dependían exclusivamente del nivel del salario, aun cuando este constituyera una parte importante de dichos ingresos y fuese, de hecho, un indicador pertinente. Pero, ¿acaso habrá aumentado el salario en el campo durante el siglo XVIII? Aunque sea difícil contestar esa pregunta, digamos por lo menos que la cuestión es dudosa. Conocer la evolución de los salarios de los obreros urbanos y agrícolas es un asunto muy complejo, y los intentos que han llevado a cabo los historiadores para determinarlos han sido, en regla general, arriesgados y cuestionables. Cuando lo han hecho, han utilizado lo que han encontrado como fuentes, y, muy a menudo, lo que encuentran es el salario del albañil. En seguida, no siempre han tenido el escrúpulo de retroceder ante la idea de asimilar a todos los asalariados -en primer lugar al asalariado agrícola- a los asalariados de la construcción, hasta concluir abusivamente que el movimiento de sus salarios era idéntico, e incluso decretar de forma arbitraria y sin complejos que se podían comparar los salarios de la construcción de un país a otro (!)

Ahora bien, desafortunadamente, como sabemos, la actividad de la construcción es atípica y su modo de remuneración es muy diferente. Por una parte, el salario del albañil depende del ritmo estacional de la demanda de dicho trabajo, que es específico y que no tiene nada que ver con la demanda de mano de obra agrícola, y depende además de la actividad del conjunto del sector y de su propia oferta de mano de obra. Para decirlo en toda su crudeza, no llama la atención que los salarios londinenses sean más altos, en una ciudad devastada por el gran incendio de septiembre de 1666. Por otro lado, si hablamos de remuneraciones, los jornaleros, o los viñateros (que no son sino jornaleros que dominan la técnica del cultivo de la viña y la fabricación del vino) no perciben un salario neto sino que son remunerados según un amplio abanico de formas de pago: compensaciones por servicios proporcionados e intercambiados y pagos en especies, al tiempo que reciben alimentos y acumulan actividades diferentes, incluso en trabajos sobre su propias parcelas o dentro de aquellas actividades de la llamada protoindustrialización. Nos hallamos entonces reducidos a conjeturas y lo mejor que podemos escribir es que las perspectivas no son muy alentadoras que digamos.

Los desperdigados datos sobre el siglo XVIII, reunidos por J. P. Poussou, sugieren un casi estancamiento de las remuneraciones en valor nominal, para la mayor parte del siglo, antes de lograr un modesto incremento al terminar el mismo. Si tomamos en cuenta el alza de precios del trigo, alimento de base del campesinado, observamos un continuo retraso de los salarios con respecto a la evolución de los precios, lo que significa claramente su retroceso en valores reales. Los cálculos establecidos de los salarios no cualificados de Bretigny (en la construcción, ahora y siempre) muestran que la paga de la jornada de trabajo habría pasado entre 1714-1715 y los últimos años del Antiguo Régimen (Hoffman, 1996, p. 223), de 15-25 sous a 18,5-27,5 sous (con un rango de variación, a finales del Antiguo Régimen, de 12-20 sous en invierno y 25-30 en verano). Es decir, un tardío, aunque ampliamente insuficiente aumento de $10 \%$, mientras que los precios galopaban, con un alza de más de $50 \%$ (Labrousse, 1933). En esas condiciones, no podemos sino quedarnos sorprendidos de que los jornaleros hubieran podido hacer frente a sus necesidades mínimas, más aun en lo que concierne el incremento de su consumo no alimenticio (Clark, 2007). La explicación sería entonces perfectamente lógica: al no aumentar sus salarios, habrían tenido que trabajar más para poder satisfacer su apetito de consumo; o 
sea, trabajar más ellos mismos, pero también obligar a trabajar a sus mujeres e hijos en el contexto de una agricultura especializada, que exigiría más brazos, o en el cuadro de una protoindustrialización, destinada a completar los recursos de los hogares (Terrier, 1996). ¿No sería entonces esa nuestra revolución industriosa?

2) Pero, ¿será esa conclusión la más plausible? Podemos dudar de ello, si consideramos el problema bajo otra óptica. $\mathrm{Al}$ respecto, se pueden formular por lo menos tres tipos de objeciones particularmente importantes. Aunque admitiésemos, como primer enfoque, que la población trabajara más, ¿deberíamos forzosamente concluir que era para consumir más? R. Allen sugiere que el esfuerzo productivo de los trabajadores respondía más bien a su voluntad de contrarrestar los efectos de la caída del salario real (Allen y Weisdorf, 2011), esto es, trabajar más, no para consumir más, sino para sobrevivir. Esto constituye una hipótesis que no se puede descartar. Sin embargo, no podemos simplemente negar que hubiera habido una mejora durante esos dos siglos, aun cuando no hubieran sido los asalariados los mayores beneficiarios de esa evolución. Por ello podemos interrogarnos sobre cómo ponderar el nuevo estatuto de consumidores de los sectores populares, si su condición se reducía a la búsqueda de los medios necesarios para mantener su nivel de vida anterior.

La explication podría ser doble. Por una parte, los pequeños campesinos habrían encontrado dichos medios gracias a los lucrativos ingresos que generó el rápido aumento del consumo parisino de vinos (Lachiver, 1991; Mireaux, 1958). Por otro lado, la introducción y difusión de nuevos objetos habrían sido favorecidas por la baja relativa de su costo. En realidad, ¿qué sabemos del nivel de precios de tales novedades? Muy poco, a tal punto que podríamos preguntarnos si el valor de aquellos productos no bajaba más rápido que el salario real. Por ello, con intensificación del trabajo o sin ella, podríamos entender entonces por qué se habría vuelto más fácil adquirirlos, lo que, agregado a la moderación de la presión fiscal y la desaparición de las catástrofes producidas por las crisis anteriores, permitiría comprender que el retroceso del salario real no fuese incompatible con la mejora del nivel de vida, gracias a una disminución de los precios industriales. Con esa hipótesis no se produciría necesariamente una proletarización de la población, contrariamente a lo que se ha indicado con anterioridad, de manera imprudente.

Al mismo tiempo, ¿acaso estamos seguros de que la gente trabajaba más? Esto puede verificarse en relación con el mundo urbano (y no para el rural), respecto del cual se han buscado índices indirectos del aumento de la presencia de los trabajadores, asalariados o no, en su lugar de trabajo. Por ejemplo, H. J. Voth, a partir de archivos judiciales, afirmó que los obreros londinenses aumentaron su tiempo de trabajo (Voth, 2000). Pero, ¿acaso habrá sido igual en el campo? Y, por otro lado, ¿qué quiere decir trabajar más tiempo? ¿Trabajar más? Quizás sí, quizás no. Uno puede trabajar mucho y trabajar más tiempo y no significa lo mismo. Por ejemplo, G. Clark dice no haber encontrado ninguna prueba tangible de aumento del tiempo de trabajo en los aserraderos especializados en la producción de madera de tejado y materiales de construcción de casas. Si la productividad se incrementó, se debió sobre todo al progreso técnico y no al tiempo de trabajo suplementario (Clark y Van der Werf, 1998), lo que introduce serias dudas sobre la posibilidad de una revolución industriosa (Clark, 2010). Además, podemos preguntarnos, ¿qué reserva de tiempo existía para que la mano de obra pudiera intensificar su esfuerzo productivo? Los tenues índices elaborados por Mireaux, para el siglo XVII en la Región de Brie, no apoyan en absoluto tal hipótesis. El tiempo de trabajo ya era elevado antes de la revolución del consumo; Mireaux habla de 200 días anuales, utilizando la Encuesta de 1717 (Mireaux, 1958). Por otro lado, si seguimos al mismo autor y la misma encuesta, se sabe que el trabajo femenino estaba bastante extendido: entre 100 y 150 días anuales. Si agregamos a ello las tareas domésticas de las que se encargaban, se puede afirmar que cualquier intensificación del trabajo femenino hubiera sido más bien una transferencia del mismo, tal vez remunerada (en vez de ser no monetizada), pero no un suplemento de trabajo.

Incluso de haberlo querido, ¿habrían tenido la posibilidad los obreros agrícolas de trabajar más? ¿Acaso sabemos si se había producido un aumento de la demanda y el número de empleos disponibles? Siempre siguiendo a Mireaux, no cabía esperar de la protoindustrialización que hubiese requerido un aumento de brazos, en una región en la que la artesanía no se había desarrollado demasiado y que más bien parecía estar declinando (Mireaux, 1958, pp. 256-257). Ahora bien, si miramos la agricultura, nos enfrentamos con un 
dilema. Se nos dice que la productividad habría aumentado, pero la explicación de ello, ¿habrá sido el aumento del tiempo de trabajo? Es probable que no, puesto que, como acabamos de verlo, se admite por lo general que el alza de la productividad no se debía necesariamente al mayor esfuerzo de los trabajadores, sino sobre todo a la innovación técnica, la que, al revés, ostentaba el mérito de reducir la cantidad de trabajo y de mano de obra necesarios. Además, es cierto que no se constata en el campo ese ahorro de mano de obra, al ser modestas las mejoras técnicas agrícolas, incluso en el siglo XVIII. Así, siendo inclusive tardía, la introducción de nuevas herramientas o la de nuevas técnicas de producción ${ }^{4}$ pudo reducir la demanda de mano de obra, pero no debemos olvidar que el progreso agrícola se debió también a la multiplicación de nuevas prácticas de laboreo agrícola (por ejemplo, los cuidados suplementarios proporcionados a la viña) o al uso incrementado de abonos y fertilizantes (Moriceau, 1994b). Y, en ese caso, los requerimientos de más trabajo y más esfuerzo hubiesen podido contrabalancear el retroceso del empleo generado por las innovaciones técnicas. Pero no podemos deducir de ello que se haya producido un aumento espectacular del tiempo global de trabajo. Aparte de que chocamos con otro obstáculo que se opone a la hipótesis de la revolución industriosa: ¿En qué medida el hipotético aumento de la demanda de los empleadores podía crear tensiones en el mercado de trabajo y estimular por ello a los trabajadores para que estos incrementasen su actividad? Seguramente dependía del número de brazos disponibles.

Ahora bien, los cálculos efectuados a partir de una muestra de aldeas de la Región de Brie (Le Mée-Orsetti y Le Mée, 1988), de donde provienen los inventarios post mortem, permiten deducir que la población se incrementó de $33 \%$ entre 1720 y 1789 y de $70 \%$ entre 1599 y 1789 , mientras que la evolución de la población de la ciudad de Meaux era más bien errática: aumento de $20 \%$ durante el siglo XVIII, pero caída de $16 \%$ al considerar los dos siglos. Esto significa que el periodo observado fue una fase de crecimiento demográfico y que no era necesario acrecentar el trabajo de cada quien, incluso para aumentar la productividad de la agricultura; solo bastó con recurrir a ella, modestamente inclusive, hurgando simplemente en esa reserva. $\mathrm{O}$, si no, es posible otra alternativa: ¿se habría constituido una sociedad dual, de dos velocidades, una con jornaleros o empresarios agrícolas sobrecargados de trabajo participantes de una sociedad de consumo naciente, y otra con una masa de individuos excluidos del mercado de trabajo, ajenos y separados, que no pudieron inscribirse en ese movimiento?

\section{CONCLUSION FINAL}

Podríamos seguir divirtiéndonos mentalmente y multiplicando las hipótesis, pero, como hemos visto, no hay nada que permita apoyar o respaldar la idea de una revolución industriosa ni la de una excepcionalidad del caso de las Provincias Unidas. Si es posible expresar un consenso general sobre la aparición y la amplitud de la revolución del consumo -que se confirma, en su totalidad, durante el siglo XVIII-, queda claro que su inicio data del siglo precedente, incluso fuera de las Provincias Unidas. Se observa asimismo que colocar la presunta segunda revolución, denominada industriosa, como vector de la revolución del consumo es por lo menos cuestionable, y que, por ende, está igualmente en entredicho el señalarla como inicio de la revolución industrial, de la que en vano buscaríamos huellas en la Región de Brie.

En realidad, nuestra propuesta apunta más bien a considerar otros dos factores que permitirían explicar la revolución del consumo sin pasar bajo las horcas caudinas de la revolución industriosa. E incluso, para redondear nuestro enfoque, se podría agregrar un tercer factor, a modo de hipótesis. El primer factor sería la evolución económica. Ya hemos visto cómo esta influía decisivamente sobre el movimiento del nivel de consumo. La crisis de mediados del siglo XVII y la de fines del mismo siglo corresponden exactamente a la caída del índice del consumo, de igual modo que las dificultades de los años 1740 coinciden con la suspensión del alza del nivel de vida. De modo inverso, el auge del siglo XVIII es concomitante con la ampliación del abanico de objetos incluidos en los inventarios post mortem, sea cual fuere el grado de ralentización que irrumpiere en vísperas de la Révolution (Labrousse, 1944; Beaur, 2000, pp. 268-272). Esto equivale a decir 
que la prosperidad es el mejor aliado del consumo, al liberar a los trabajadores de la preocupación del pan de cada día y, al mismo tiempo, al contribuir a la expansión de las posibilidades de trabajo (mejores cosechas que significan más cereales que segar, más granos para batir; una demanda más grande que significa más lana que hilar, más hilados que coser y tejer, etc.)

Pero no son los asalariados los que más se benefician con esta revolución, sino los laboureurs, tal como podría esperarse cuando se conoce el proceso de enriquecimiento de ese grupo social, por ejemplo, de la Región de la Isla de Francia o de la vecina Beauce (Moriceau, 1994a; Farcy, 1989). No obstante, son los grupos sociales de burgueses/comerciantes/artesanos los que, más aun que los laboureurs, mejoran su estilo de vida. ¿Será porque ha habido una intensificación del trabajo de los comerciantes y artesanos? Es posible, pero no probable. Miremos otra vez las curvas. Son ellos los que procesan la caída de la segunda mitad del siglo XVII. En ellos se observan los efectos del marasmo de la producción artesanal y el comercio de dicho periodo, en marcado contraste con el auge del siglo XVIII. No ocurre lo mismo con los agricultores arrendatarios laboureurs, los que, aunque sea a trompicones, siguen vendiendo sus cosechas y resistiendo a la mala coyuntura, antes de aprovechar plenamente las bondades del siglo XVIII. El contexto les es favorable: alza de precios, salarios a media asta, una renta perezosa hasta 1768 ; los datos de los contratos de Notre Dame de París durante dos siglos (Hoffman, 1996, 90) así lo confirman. Aunque no sea necesariamente el consumo su prioridad, comparado con la inversión, e incluso con la educación e instalación de los hijos (Moriceau y Postel-Vinay, 1992, pp. 296-299), son ellos los principales beneficiarios de esa revolución. Pero, ¿se puede afirmar que los rentistas y "burgueses” hayan aumentado verdaderamente su esfuerzo productivo? ¿No habrá sido más bien que lograron capturar una parte de las ganancias de productividad gracias a un incremento que lograron imponer a la renta y el diezmo? ¿No asistimos justamente a un despegue de la renta, con un aumento del $100 \%$ en 10 años, a partir de 1768 (Béaur, 1982)? Todo se encadena y encaja sincrónicamente en el mundo real, sin necesidad de invocar ningún concepto de revolución industriosa.

Pero hay un segundo factor, más difícil de detectar a no ser que se utilicen fuentes cualitativas. Se trata de observar en los inventarios la aparición de productos nuevos o la aceleración de su uso. Su ausencia anterior en los registros podía ser sinónimo de inexistencia o de accesibilidad dificultosa. Durante el siglo XVIII, sobre todo, aumenta la circulación de mercancías, gracias a la configuración de más tupidas y mejor estructuradas redes de comerciantes. El comercio colonial se sigue desarrollando y transporta nuevas mercancías, lo que hace que productos antes desconocidos, o conocidos, pero fuera del ámbito de la Región de Brie, se pongan ahora a su alcance, puedan ser adquiridos a precios no exorbitantes y aparezcan en los inventarios, con ventaja para aquellos lugares ubicados cerca de los sitios de producción, de distribución o del mar. No es sorprendente que una ciudad como Ámsterdam y sus campiñas se hayan apropiado más rápidamente de las novedades y que se haya producido un desfase temporal entre las Provincias Unidas y las zonas menos irrigadas por el comercio, sin que haya por ello que invocar una revolución industriosa.

$\mathrm{Al}$ respecto subsiste una confusión, que sus historiadores se emplean en mantener, entre Holanda y las Provincias Unidas. Holanda se sitúa en el área de atracción de las grandes ciudades mercantiles de las Provincias Unidas, con Ámsterdam en primer lugar, pero no únicamente; en realidad, Ámsterdam es una pequeña porción de ese territorio. Allí se concentran, claro está, la riqueza y la prosperidad, pero, ¿qué ocurre cuando nos alejamos de esa zona privilegiada? Es como París con sus campiñas, en donde la ciudad concentra también la actividad económica y el alto nivel de consumo y vida para su población. Al alejarnos de París, por ejemplo, en la Región de Brie, también encontramos una elevación del nivel de vida, pero también un seguro desfase con respecto a la metrópolis. Por ello, si cupiese el ejercicio comparatista, se tendría que efectuar entre París y Ámsterdam, por un lado, y entre sus campiñas respectivas, por otro, o con otras grandes ciudades europeas; o tal vez entre zonas menos afortunadas, igualmente relacionadas (o no) con centros económicos y/o de consumo.

Ahora bien, se podría invocar un tercer factor: la voluntad política de "potenciar" el consumo y hacer que los agentes económicos (o sea productivos) se volvieran también consumidores, con el fin de relanzar la 
actividad. Obviamente, habría que aportar las pruebas de esa hipótesis, situadas tal vez en la prolongación de las ideas de Pierre de Boisguilbert, quien preconizaba el crecimiento de la demanda global, con la finalidad de combatir la recesión de fines del siglo XVII. O las de Bernard Mandeville, quien ensalzaba en la Fábula de las Abejas (Vicios privados, Beneficios públicos) de 1705, la utilidad de los vicios privados como consumidores de bienes de lujo, y, por ende, como factores estimulantes de la economía. ¿Habrá tomado en cuenta la Monarquía (bastante antes del vuelco keynesiano) tal opción política, cuando los economistas clásicos de entonces no cesaban de clamar que era la oferta la que creaba la demanda? O quizás, de forma intuitiva, ¿no habrá sido por paternalismo monárquico que se hubiese deseado acrecentar el acceso a los bienes que el mercado ofrecía, tal vez por razones sociales, económicas o morales? Al final de cuentas, ¿no iban justamente en ese mismo sentido la política de la monarquía francesa (y la del resto de Estados), el fomento del comercio colonial, la conquista y explotación de tierras "nuevas", así como el abastecimiento de productos y mercancías procedentes de otros continentes? El estímulo y el apoyo brindados a las compañías comerciales por Estados y monarquías, aunque fuese durante mucho tiempo en un sentido esencialmente mercantilista, ¿no le daba ocasión al común de los habitantes, aunque solo fuera de rebote, de consumir más? ¿No había que aumentar el consumo para sostener la viabilidad y las ganancias de las Compañías de Comercio? La cuestión queda planteada.

Pero volvamos a las raíces de la sociedad de consumo, puesto que de eso se trata. Efectivamente, grande es la tentación de vincular el consumo con el poder de compra gracias al trabajo, y, en realidad, ¿cómo ignorar dicha relación? Pero, ¿habrá que hacerlo fundándola en una nueva actitud de los consumidores? ¿Se tiene que suponer que estos se pusieron a trabajar más para consumir más? Pensamos que el vínculo es más sutil. Ya con anterioridad, Mathieu Arnoux había abogado en favor de una nueva actitud respecto al trabajo durante los siglos XI-XIII, como fundamento explicativo del auge del medioevo europeo (Arnoux, 2012). Y ahora Jan de Vries nos afirma que los siglos XVII-XVIII constituirían un largo periodo de trabajo cada vez más intenso, lo que significaría que la historia europea sería la de una laboriosa y penosa entrada al trabajo, entre los siglos XI-XIX, de sus poblaciones, con un paréntesis entre el siglo XIV y quizás el siglo XVI. Pero, ¿no será tal vez que dichas poblaciones siempre quisieron consumir más pero no pudieron, ya sea porque no se les proporcionaba nada nuevo o quizás porque sus recursos simplemente no se lo permitían?

\section{BibLIOGRAFÍA}

Allen, R. C. y Weisdorf, J. L. (2011), Was there an "industrious revolution" before the industrial revolution? An empirical exercise for England, c. 1300-1830. Economic History Review, 64 (3), 715-729.

Arnoux, M. (2012). Le Temps des laboureurs: travail, ordre social et croissance en Europe (xi.-xiv. siècle). Paris: Albin Michel.

Baulant, M. (1979). L’Analyse par ordinateur des inventaires après décès de la région de Meaux. En B. Vogler (Ed.), Les actes notariés, source de l'histoire sociale xvi.-xix. siècle (pp. 197-204). Strasbourg: Istra.

Baulant, M. (1980a). Typologie des inventaires après décès. En A. van der Woude y A. Schuurman (Ed.), Probate Inventories. A New Source for the Historical Study of Wealth, Material Culture and Agriculture Development (pp. 33-42). Wageningen [Netherlands], A.A.G. Bijdragen, 23 y Utrecht: Hes Studia Historica.

Baulant, M. (1980b). Enquête sur les inventaires après décès autour de Meaux aux xvii. et xviii. siècles. En A. van der Woude y A. Schuurman (Ed.), Probate Inventories. A New Source for the Historical Study of Wealth, Material Culture and Agriculture Development (pp. 141-148). Wageningen [Netherlands], A.A.G. Bijdragen, 23 y Utrecht: Hes Studia Historica y en A. Schweitz, G. Béaur, A. Varet-Vitu (2006). Meaux et ses campagnes. Vivre et survivre dans le monde rural sous l'Ancien Régime (pp. 263-270). Rennes: Presses universitaires de Rennes.

Baulant, M. (1989). L'Appréciation du niveau de vie. Un problème, une solution, Histoire y Mesure, 4-3/4, 267-302, y en A. Schweitz, G. Béaur y A. Varet-Vitu (2006). Meaux et ses campagnes. Vivre et survivre dans le monde rural sous l'Ancien Régime (pp. 287-317). Rennes: Presses universitaires de Rennes. 
Baulant, M. (1990). Niveaux de vie et reproduction sociale. Les paysans de la région de Meaux (1751-1790). En G. Bouchard y J. Goy (Ed.), Famille, économie et société rurale en contexte d'urbanisation (xvii.-xx. siècle) (pp. 199-211). Chicoutimi y Paris: SOREP y Éditions de l'EHESS.

Baulant, M. (1992). Niveau de vie des familles rurales dans la Brie du xviii. siècle. En R. Bonnain, G. Bouchard y J. Goy (Ed.), Transmettre, hériter, succéder. La reproduction familiale en milieu rural, France Québec, xviii.-xx. siècle (pp. 135-151). Lyon: Presses universitaires de Lyon.

Baulant, (2001). Jalons pour une histoire du "costume commun". L'exemple de Meaux (1590-1670). Histoire et Mesure, 16 (1/2), 3-56.

Baulant, M., Schuurman, A. y Servais P. (Ed.) (1988). Inventaires après décès et ventes de meubles. Apports à une histoire de la vie économique et quotidienne, xiv..xix. siècle. Louvain-la-Neuve: Academia, 1988.

Béaur, G. (1982). Le Mouvement annuel de la rente foncière chartraine 1760-1780. En J. Goy et E. Le Roy Ladurie (Ed.), Prestations paysannes, dîmes, rente foncière et mouvement de la production agricole à l'époque préindustrielle (491-501). Paris-La Haye: Mouton.

Béaur, G. (2000). Histoire agraire de la France au xviii. siècle. Inerties et changements dans les campagnes françaises entre 1715 et 1815. Paris: SEDES.

Béaur, G. (2017a). La Révolution industrieuse introuvable. Revue d'Histoire Moderne et Contemporaine, 64 (4), 7-24.

Béaur, G. (2017b). Niveau de vie et révolution des objets dans la France d'Ancien Régime. Meaux et les campagnes aux XVIIle et XVIIIe siècles. Revue d'Histoire Moderne et Contemporaine, 64 (4), 25-58.

Béaur, G. (2018). Els inventaris Post Mortem, eines per Mesurar el nivell de vida. La vila de Meaux i el seu entorn rural van conèixer una revolució del consum i/o una revolució industriosa en el transcurs dels segles XVII i XVIII?. En B. Moreno Claverías. (Ed.), Els inventaris post-mortem. Una font per a la historia económica i social (pp. 143-162). Girona: Biblioteca d'Història Rural, Associació d'Història Rural de les Comarques Gironines-Centre de Recerca d'Història Rural de la Universitat de Girona-Documenta Universitaria.

Clark, G. (2007). The Long march of history: Farm wages, population and economic growth, England, 1209-1869. Economic History Review, 60 (1), 97-135.

Clark, G. (2010). The Consumer revolution: turning point in human history, or statistical artifact? https://papers.ss rn.com/sol3/papers.cfm?abstract_id $=1653155$.

Clark, G. y van der Werf, Y. (1998). Work in progress? The industrious revolution. Journal of Economic History, 58 (3), 830-843.

Congost, R., Esteve, E. y Serramontmany, A. (2017). L'Evolution du niveau de vie des pauvres. La Petite paysannerie de la région de Gérone (1750-1800). Revue d'Histoire Moderne et Contemporaine, 64 (4), 84-104.

Cornette, J. (1989). La Révolution des objets. Le Paris des inventaires après-décès (xvii.-xviii. siècles). Revue d'Histoire Moderne et Contemporaine, 36 (3), 476-486.

de Vries, J. (1994). The industrial revolution and the industrious revolution. Journal of Economic History, 54 (2), 249-270.

de Vries, J. (2008). The Industrious Revolution. Consumer Behavior and the Household Economy, 1650 to the Present. Cambridge: Cambridge University Press.

Durães, A. (2012). The Empire within. Consumption in Lisbon in eighteenth century and first half of the nineteenth century. Histoire et Mesure, 27 (2), 165-196.

Farcy, J.-C. (1989). Les Paysans beaucerons au xix. siècle. Chartres, Société Archéologique d'Eure-et-Loir.

Hayami, A. (2015). Japan's Industrious Revolution. Economic and Social Transformations in the Early Modern Period. Tokyo: Springer.

Herment, L. (2017). Y a-t-il eu une révolution industrieuse dans le Bassin parisien au xix. siècle?. Revue d'Histoire Moderne et Contemporaine, 64 (4), 105-33.

Hoffman, P. T. (1996). Growth in a Traditional Society. The French Countryside 1450-1815. Princeton: Princeton University Press. 
Labrousse, E. (1984) [1933]. Esquisse du mouvement des prix et des revenus en France au xviii. siècle. Paris-Montreux: Éditions des archives contemporaines.

Labrousse, E. (1990) [1944]. La Crise de l'économie française à la fin de l'Ancien Régime et au début de la Révolution. Paris: PUF.

Lachiver, M. (1982). Vin, vigne et vignerons en région parisienne du xvii. au xix. siècle. Pontoise: Société historique et archéologique de Pontoise, du Val d'Oise et du Vexin.

Lachiver, M. (1991). Les Années de misère. La famine au temps du Grand Roi, 1680-1720. Paris: Fayard.

Le Mée-Orsetti, M. y Le Mée, R. (1988). Paroisses et communes de France: dictionnaire d'histoire administrative et démographique, 77, Seine-et-Marne. Paris: Éditions du CNRS.

McCants, A. E. C. (2007). Exotic Goods, Popular Consumption, and the Standard of Living: Thinking about Globalization in the Early Modern World. Journal of World History, 18 (4), 433-462.

McKendrick, N. (1982). The Commercialization of Fashion. En J. Brewer, N. McKendrick y J. H. Plumb (Ed.), The Birth of a Consumer Society: The Commercialization of Eighteenth-Century England, (pp. 34-99). London: Europa Publications Limited,.

Minard, P. (2000). La Révolution des objets. Une aventure humaine du xviii. siècle. Critique, 632-633, 64-73.

Mireaux, É. (1958). Une Province française au temps du Grand Roi: la Brie. Paris: Hachette.

Moreno Claverías, B. (Ed.), (2018). Els inventaris post-mortem. Una font per a la història económica i social. Girona: Biblioteca d'Història Rural, Associació d'Història Rural de les Comarques Gironines-Centre de Recerca d'Història Rural de la Universitat de Girona-Documenta Universitaria.

Moreno Claverías, B. (2017). Révolution industrieuse ou simple survie? Stratégies familiales dans une zone protoindustrielle de Catalogne au xviii. siècle. Revue d'Histoire Moderne et Contemporaine, 64 (4), 59-83.

Moriceau, J.-M. (1994a). Les Fermiers del'Île-de-France. Ascension d'un patronat agricole (xv.-xviii. siecle). Paris: Fayard.

Moriceau, J.-M. (1994b). Au Rendez-vous de la "Révolution agricole" dans la France du xviii. siècle. À propos des régions de grande culture. Annales HSS, 49 (1), 27-63.

Moriceau, J.-M. y Postel-Vinay, G. (1992). Ferme, entreprise, famille. Grande exploitation et changements agricoles: les Chartier (xvii.-xix. siècles). Paris: Éditions de l'EHESS.

Overton, M., Whittle, J., Dean, D. y Hann, A. (2004). Production and Consumption in English Households, 1600-1750. Londres: Routledge.

Pardailhé-Galabrun, A. (1988). La Naissance de l'intime. 3000 foyers parisiens, xvii.-xviii. siècles. Paris: Presses Universitaires de France.

Pellegrin, N. (1986). L'Habillement rural en Poitou au xviii. siècle, d'après les inventaires après décès. En J. Goy y J.P. Wallot (Ed), Évolution et éclatement du monde rural. Structures, fonctionnement et évolution différentielle des sociétés rurales françaises et québécoises, xvii.-xx. siècle (pp. 475-485). Paris y Montréal: Éditions EHESS y Presses de l'université de Montréal.

Péret, J. (1986). Les Meubles ruraux en Haut-Poitou au xviii. siècle, d'après les inventaires après décès. En J. Goy y J.P. Wallot (Ed.), Évolution et éclatement du monde rural. Structures, fonctionnement et évolution différentielle des sociétés rurales françaises et québécoises, xvii.-xx. siècle (pp. 487-498). Paris y Montréal: Éditions EHESS y Presses de l'université de Montréal.

Pérez-García, J. M. (1997). Niveaux de vie et traditions culturelles dans les campagnes du León entre 1700 et 1850. Histoire et sociétés rurales, 8, 61-92.

Roche, D. (1981). Le Peuple de Paris. Essai sur la culture populaire au xviii. siècle. Paris: Aubier-Montaigne.

Roche, D. (1997). Histoire des choses banales. Naissance de la consommation dans les sociétés traditionnelles (xvi.-xix. siecle). Paris: Fayard.

Shammas, C. (1990). The Pre-Industrial Consumer in England and America. Oxford: Clarendon.

Schuurman, A. (2011). Material culture research revisited. Comparing the worlds of goods, Working paper en Secondes Journées d'histoire des campagnes européennes de Ca Tron sur "Niveau de vie et "révolution des objets" dans les campagnes (xvii.-xix. siècle). 
Sobrado Correa, H. (2003). Los inventarios post-mortem como fuente privilegiada para el estudio de la historia de la cultura material en la edad moderna. Hispania, 63-215, 825-861.

Terrier, D. (1996). Les Deux âges de la proto-industrie. Les tisserands du Cambrésis et du Saint-Quentinois, 1730-1880. Paris: Éditions de l'EHESS.

van der Woude, A. y Schuurman, A. (Ed.) (1980), Probate Inventories. A New Source for the Historical Study of Wealth, Material Culture and Agriculture Development. Wageningen [Netherlands], A.A.G. Bijdragen, 23 y Utrecht: Hes Studia Historica.

Voth, H.-J. (2000). Time and Work in England, 1750-1830. Oxford: Clarendon.

Weatherill, L. (1988). Consumer Behaviour and Material Culture in Britain, 1660-1760. Londres: Routledge.

Wilmart, M. (2013). Meaux au Moyen Âge. Une ville et ses hommes du xii. au xv. siècle. Montceaux-lès-Meaux: Fiacre.

\section{Notas}

1 Traducción de Pablo F. Luna.

2 Región vecina de la región parisina.

3 La base de datos cuenta con 100 inventarios para el periodo 1580-1650 (21 para Meaux), 382 para 1651-1700 (40 para Meaux), 384 para 1701-1750 (45 para Meaux), 266 para 1751-1790 (70 para Meaux).

4 Primero la zapa, luego la guadaña, en seguida arados más rendidores, aparejados por animales mejor alimentados. 